\section{NASDA ADVISES ON RECEPTIONISTS' UNIFORMS}

Dental practice owners who provide their reception staff with uniforms should make sure that each garment bears the practice logo or name. According to tax legislation, unless there is a logo or name on each part of the uniform, it will be treated as a benefit in kind.

The National Association of Specialist Dental Accountants (NASDA) is alerting the dental profession to the legislation as Her Majesty's Revenue and Customs (HMRC) tax inspectors who carry out dental practice inspections may ask about staff uniforms.

Receptionists' uniforms bought by the employer are automatically sub- ject to tax at the full value unless there is a name or logo embroidered onto each tunic, jacket, shirt, or pair of trousers.

HMRC carries out occasional spot checks, and tax inspectors are also likely to ask whether team members are getting free dental treatment. This is also deemed to be a benefit in kind.

'Inadvertently, HMRC seems to be helping dental practices with their PR,' said Chartered Accountant and dental business strategist Alan Suggett. 'Plenty of exposure for the logo or name should help make a positive impact on patients.'

\title{
CAMPAIGN TO SWAP SWEETS FOR HEALTHY TREATS
}

The British Dental Trade Association (BDTA) is supporting the Department of Health's (DH's) Change4Life (C4L) initiative through a campaign which promotes the benefits of a healthy mouth to overall good health and encourages families to visit the dentist.

The BDTA campaign, which is being rolled out from this month using the strapline 'Kick out the sweets, bring on the healthy treats', is supported by a collection of colourful cartoon characters. A poster, designed to encourage children to swap sugary foods with healthy alternatives and persuade parents to introduce healthy foods into their children's and their own diets, will be sent to dental practices across England and Wales (Scotland and Northern Ireland have not yet adopted $\mathrm{C} 4 \mathrm{~L})$.
Practices will also be sent a questionnaire and members of the dental team will be asked to complete them with the involvement of their children. Stickers will be given to children who get involved and participating practices will have the chance to win one of four $£ 500$ vouchers to spend with a BDTA member company.

C4L is the social marketing component of the Government's much broader response to the rise in obesity and was launched to the public in January 2009.

'This initiative allows us to communicate positive messages to patients in the dental practice waiting room and highlight the connection between a healthy mouth and good overall health,' said Tony Reed, BDTA Executive Director.
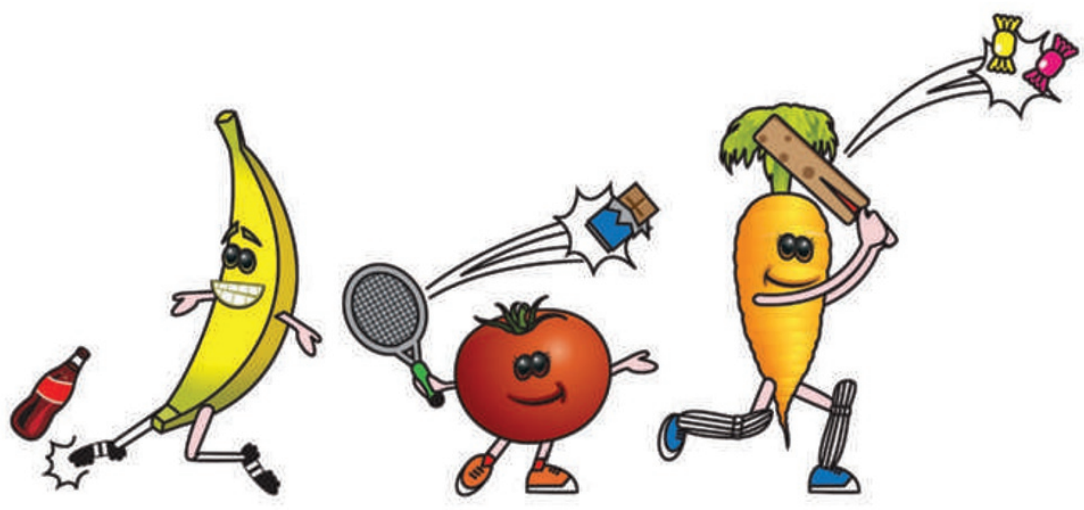

\section{MANCHESTER CONSULTANT AWARDED CHAIR}

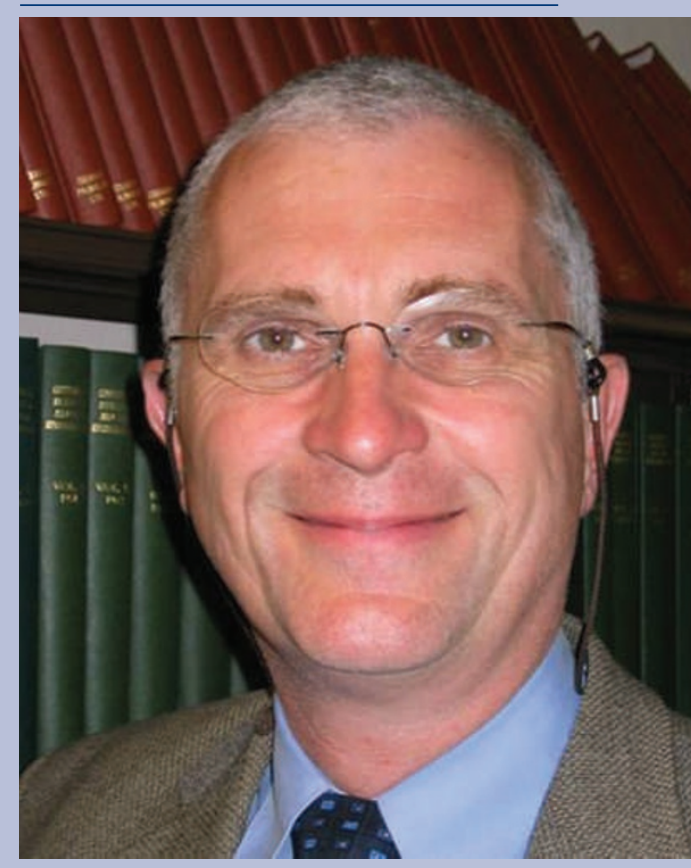

Dr Keith Milsom has been awarded a Chair in Population Oral Health at the University of Manchester.

The newly appointed Professor is also the Operational Director of the Oral Health Unit (OHU) of the National Primary Care Research \& Development Centre (NPCRDC) at the University of Manchester where he was instrumental in obtaining funding to establish the unit in 2004.

Working alongside Professor Martin Tickle in the internationally recognised unit, Professor Milsom has published over 50 research articles in peer reviewed journals and has received research funding in excess of £3.2 million. Locally he works as a Consultant in Dental Public Health for Halton et St Helens and Warrington Primary Care Trusts. He takes the lead for oral health strategy development and works with the commissioning team on the delivery of programmes designed to improve access to NHS dental services, improve oral health and reduce dental health inequalities.

'We hope that [Professor Milsom's] work continues to bring research success not only for the University and OHU but the dental evidence base as a whole,' said Professor Tickle, OHU Research Director. 